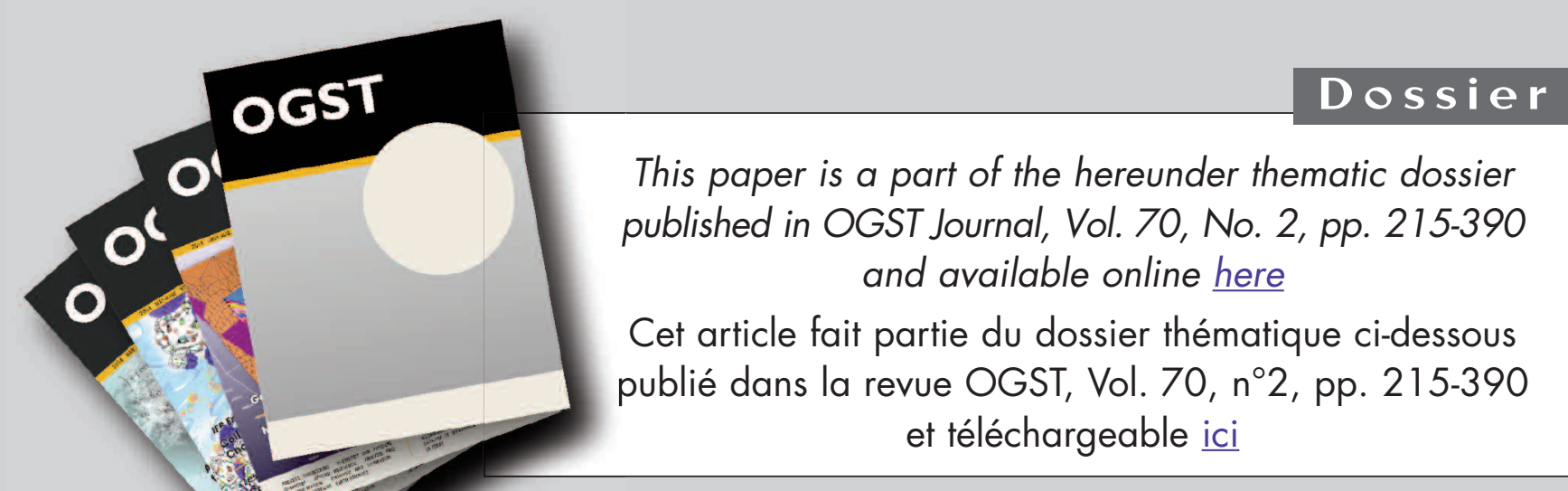

DOSSIER Edited by/Sous la direction de : B. Dewimille

Fluids-Polymers Interactions: Permeability, Durability

Interactions fluides polymères : perméabilité, durabilité

Oil \& Gas Science and Technology - Rev. IFP Energies nouvelles, Vol. 70 (2015), No. 2, pp. 215-390

Copyright (C) 2015, IFP Energies nouvelles

$215>$ Tribute to Yves Chauvin Hommage à Yves Chauvin

S. Candel and 0 . Appert

$219>$ Editorial

G. Kimmerlin

227 > Gas Permeation in Semicrystalline Polyethylene as Studied by Molecular Simulation and Elastic Model

Perméation de gaz dans le polyéthylène semi-cristallin par simulation moléculaire et modèle élastique

P. Memari, V. Lachet and B. Rousseau

237 > Reinforcement of the Gas Barrier Properties of Polyethylene and Polyamide Through the Nanocomposite Approach: Key Factors and Limitations

Renforcement des propriétés barrière aux gaz de matrices polyéthylène et polyamide par l'approche nanocomposite : facteurs clés et limitations E. Picard, J.-F. Gérard and É. Espuche

251 > Diffuso-Kinetics and Diffuso-Mechanics of Carbon Dioxide / Polyvinylidene Fluoride System under Explosive Gas Decompression: Identification of Key Diffuso-Elastic Couplings by Numerical and Experimental Confrontation

Cinétique de diffusion et comportement diffuso-mécanique du système dioxide de carbone / polyfluorure de vinylidène sous décompression explosive de gaz : identification des couplages diffuso-élastiques majeurs par confrontation numérique et expérimentale

J.-C. Grandidier, C. Baudet, S. A. E. Boyer, M.-H. Klopffer and L. Cangémi

267 > Characterization of Polymer Layered Silicate Nanocomposites by Rheology and Permeability Methods: Impact of the Interface Quality

Caractérisation de nanocomposites polymère silicate par des méthodes de rhéologie et de perméabilité : rôle de la qualité de l'interface

R. Waché, M.-H. Klopffer and S. Gonzalez

$279>$ Evaluation of Long Term Behaviour of Polymers for Offshore Oil and Gas Applications

Durabilité des polymères pour application pétrolière offshore

P.-Y. Le Gac, P. Davies and D. Choqueuse

$291>$ Development of Reactive Barrier Polymers against Corrosion for the Oil and Gas Industry: From Formulation to Qualification through the Development of Predictive Multiphysics Modeling

Développement de matériaux barrières réactifs contre la corrosion pour l'industrie pétrolière : de la formulation à la qualification industrielle en passant par le développement de modèles multiphysiques prédictifs

X. Lefebvre, D. Pasquier, S. Gonzalez, T. Epsztein, M. Chirat and F. Demanze
$305>$ Development of Innovating Materials for Distributing Mixtures of Hydrogen and Natural Gas. Study of the Barrier Properties and Durability of Polymer Pipes

Développement de nouveaux matériaux pour la distribution de mélanges de gaz naturel et d'hydrogène. Étude des propriétés barrière et de la durabilité de tubes polymères

M.-H. Klopffer, P. Berne and É. Espuche

317 > New Insights in Polymer-Biofuels Interaction

Avancées dans la compréhension des interactions polymères-biocarburants E. Richaud, F. Diouani, B. Fayolle, J. Verdu and B. Flaconneche

$335>$ Biofuels Barrier Properties of Polyamide 6 and High Density Polyethylene Propriétés barrière aux bio essences du polyamide 6 (PA6) et du polyéthylène haute densité (PEHD)

L.-A. Fillot, S. Ghiringhelli, C. Prebet and S. Rossi

353 > Permeability of EVOH Barrier Material used in Automotive Applications: Metrology Development for Model Fuel Mixtures

Perméabilité d'un matériau barrière EVOH utilisé dans des applications automobiles : développement métrologique pour des mélanges modèles de carburants

J. Zhao, C. Kanaan, R. Clément, B. Brulé, H. Lenda and A. Jonquières

367 > Effects of Thermal Treatment and Physical Aging on the Gas Transport Properties in Matrimid ${ }^{\circledR}$

Les effets du traitement thermique et du vieillissement physique sur les caractéristiques du transport au gaz dans le Matrimid ${ }^{\circledR}$

L. Ansaloni, M. Minelli, M. Giacinti Baschetti and G. C. Sarti

381 > Separation of Binary Mixtures of Propylene and Propane by Facilitated Transport through Silver Incorporated Poly(Ether-Block-Amide) Membranes Séparation de mélanges binaires de propylène et de propane par transport au travers des membranes de poly(éther-blocamide) incorporant de l'argent R. Surya Murali, K. Yamuna Rani, T. Sankarshana, A. F. Ismail and S. Sridhar 


\title{
Development of Reactive Barrier Polymers against Corrosion for the Oil and Gas Industry: From Formulation to Qualification through the Development of Predictive Multiphysics Modeling
}

\author{
X. Lefebvre ${ }^{1 *}$, D. Pasquier ${ }^{2}$, S. Gonzalez ${ }^{2}$, T. Epsztein ${ }^{3}$, M. Chirat ${ }^{3}$ and F. Demanze ${ }^{3}$ \\ ${ }^{1}$ IFP Energies nouvelles, 1-4 avenue de Bois-Préau, 92852 Rueil-Malmaison - France \\ 2 IFP Energies nouvelles, Rond-point de l'échangeur de Solaize, BP 3, 69360 Solaize - France \\ ${ }^{3}$ TECHNIP, rue Jean Huré, BP 7, 76580 Le Trait - France \\ e-mail: xavier.lefebvre@ifpenergiesnouvelles.fr \\ * Corresponding author
}

\begin{abstract}
Corrosion is a key issue for operators in the oil and gas industry since production fluids contain some water and both $\mathrm{CO}_{2}$ and $\mathrm{H}_{2} \mathrm{~S}$ acid gases. In this context, this paper illustrates the development of a reactive barrier polymer against corrosion by $\mathrm{H}_{2} \mathrm{~S}$ of offshore flexible pipes. The role of this reactive material, called anti- $\mathrm{H}_{2} \mathrm{~S}$ material, is to avoid $\mathrm{H}_{2} \mathrm{~S}$ reaching the structural steel layers of the flexible pipe during the whole service life of the structure, usually 20 years, and hence to place the steel layers in a sweet service environment. Placed between the existing pressure sheath and the steel layers, the anti- $\mathrm{H}_{2} \mathrm{~S}$ material has the ability to neutralize $\mathrm{H}_{2} \mathrm{~S}$ during its diffusion within the material. The neutralization is ensured by an irreversible chemical reaction on reactive components that are dispersed in the material. The raw material selection is based on both accurate requirements for their use in a flexible pipe and expected performances in a sour service environment over a long period of time. Some laboratory qualifications and experimental techniques are used to qualify the behavior of the material and build the material database. A dedicated multiphysics model is developed based on the coupling of permeation mechanisms and gas-solid reactions. Qualification of both the material and the model is performed thanks to middle-scale and full-scale tests conducted in representative sour service conditions.
\end{abstract}

Résumé - Développement de matériaux barrières réactifs contre la corrosion pour l'industrie pétrolière : de la formulation à la qualification industrielle en passant par le développement de modèles multiphysiques prédictifs - La corrosion liée à la présence de gaz acides tels que $\mathrm{CO}_{2}$ et $\mathrm{H}_{2} \mathrm{~S}$ en présence d'eau dans les effluents pétroliers est un enjeu majeur pour les opérateurs pétroliers. C'est dans ce contexte que cet article décrit le développement d'un matériau barrière réactif permettant de limiter la corrosion par $\mathrm{H}_{2} \mathrm{~S}$ des flexibles offshore. Le rôle de ce matériau barrière, appelé matériau anti- $\mathrm{H}_{2} \mathrm{~S}$, consiste à empêcher l' $\mathrm{H}_{2} \mathrm{~S}$ d'atteindre les éléments métalliques structuraux du flexible pendant toute sa durée de vie, généralement 20 ans. De cette manière, les éléments métalliques bénéficient d'un environnement « sweet service », peu agressif en terme de corrosion. Placé entre l'actuelle gaine de pression et les éléments métalliques, le matériau anti- $\mathrm{H}_{2} \mathrm{~S}$ a la faculté de pouvoir neutraliser $l^{\prime} \mathrm{H}_{2} \mathrm{~S}$ pendant sa diffusion au sein même du matériau. La neutralisation est assurée par une réaction chimique irréversible sur des charges réactives dispersées au sein

This is an Open Access article distributed under the terms of the Creative Commons Attribution License (http://creativecommons.org/licenses/by/4.0), which permits unrestricted use, distribution, and reproduction in any medium, provided the original work is properly cited. 
du matériau. Les matières premières constitutives de ce matériau sont sélectionnées selon leur performance en milieu fortement corrosif " sour service ", tout en garantissant leur compatibilité avec les applications flexibles offshore. La qualification du matériau à l'échelle du laboratoire est décrite ainsi que les techniques qui nous permettent d'alimenter la base de données nécessaire à l'identification d'un modèle. Un modèle multiphysique dédié a été développé pour décrire les couplages entre les mécanismes de diffusion-réaction. La qualification du matériau et du modèle est effectuée sur la base de résultats d'essais conduits en conditions représentatives, et réalisées sur éléments de structure et sur structures réelles.

\section{INTRODUCTION}

Corrosion is a key issue for operators in the oil and gas industry. In production systems, the production fluid usually contains a hydrocarbon phase, some water, and varying concentrations of $\mathrm{CO}_{2}$ and $\mathrm{H}_{2} \mathrm{~S}$. Both $\mathrm{CO}_{2}$ and $\mathrm{H}_{2} \mathrm{~S}$ are acid gases; therefore, when associated with water, they lead to the formation of a corrosive environment.

Corrosion mechanisms resulting from the presence of these two acid gases have their own characteristics [1-8] (Sulfide Stress Cracking - SSC, Hydrogen-Induced Cracking - HIC). In particular, the presence of wet $\mathrm{H}_{2} \mathrm{~S}$ promotes and exacerbates many types of environmental cracking. These types of cracking may become an integrity concern and hence require a specific metallurgical design or operational precautions. These wet $\mathrm{H}_{2} \mathrm{~S}$ service conditions are called sour service conditions, in contrast with sweet service conditions where no specific metallurgical design is normally required. Sour service conditions lead to high corrosion rates by SSC and environmental fracture due to hydrogen atom uptake in the steel (HIC).

Nevertheless, metallurgical or operational recommendations do not always result in competitive solutions. On one hand, specific steel grades are more expensive and their use results in non-optimum structure design due to the low mechanical properties of sour service steel grades compared with sweet service ones. On the other hand, operational precautions can be very restrictive and can be detrimental from a technical and economic point of view. That is the reason why the opportunity to use sweet service steel grades in sour service environments is a major challenge for the oil and gas production industry.

A corrosive environment is both $\mathrm{H}_{2} \mathrm{~S}$ and $\mathrm{CO}_{2}$ contentdependent and the synergistic effects of these two species are a point of consideration [1-10]. Three domains are usually defined in the oil and gas industry: the $\mathrm{H}_{2} \mathrm{~S}$ sour regime domain, the $\mathrm{CO}_{2}+\mathrm{H}_{2} \mathrm{~S}$ mixed regime domain, and the $\mathrm{CO}_{2}$ sweet regime domain [8]. As a result, a $\mathrm{H}_{2} \mathrm{~S}$-free environment is always considered as a sweet service environment. That is the reason why we focus on the neutralization of this species in production systems.
This work was carried out in a collaboration between IFP Energies nouvelles and Technip.

Two main types of pipes are used in the oil and gas production industry: flexible and rigid pipes. In rigid pipes, the production fluid is usually in contact with the structural steel, and although some limitations exist the thickness of the pipe and the metallurgical composition of the steel can usually be determined so that the pipe will resist sour service conditions.

Technip's flexible pipes are mainly used when flexibility is needed, for offshore production in particular. Flexibility is provided by the multilayer structure of the pipe. During manufacturing, laying and operation, each function of the flexible pipe is provided by an unbonded layer. Figure 1 presents a conventional flexible pipe made of the following layers:

- the first layer of a rough bore structure is a carcass (1) made of stainless steel, in direct contact with the transported fluid and sustaining the external pressure;

- the second layer is made of a leakproof continuous polymer layer and is called the pressure sheath (2);

- the third layer sustains internal pressure thanks to a steel vault wire (3) spiralled at short pitch. For high-pressure applications an additional layer called a spiral can be added between the first vault layer and the armor layers.

- the armor layers (4) are made of one or two pairs of helicoidally spiralled steel wires and designed to ensure tensile load resistance;

- the tightness of the annulus regarding the external environment is provided by an external sheath (5) made of polymer;

- if necessary, the thermal performances of the flexible pipe can be improved by a second annulus composed of syntactic foam tapes (6).

The polymer pressure sheath protects the carbon steel layers sustaining internal pressure and axial tension from any direct contact with the fluid transported in the bore. However, due to the intrinsic properties of polymer materials, active components such as water, carbon dioxide and hydrogen sulfide will permeate through the polymer pressure sheath over a long period of time $[11,12]$. The design of 
(1)

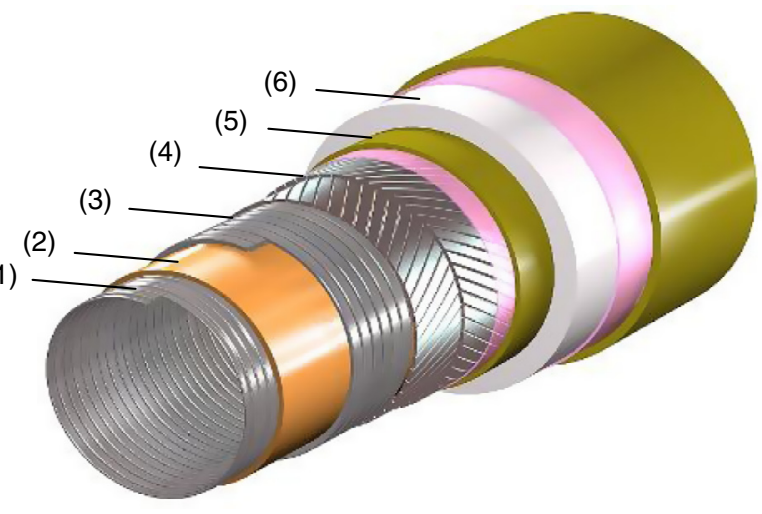

Figure 1

Layers of a conventional flexible pipe.

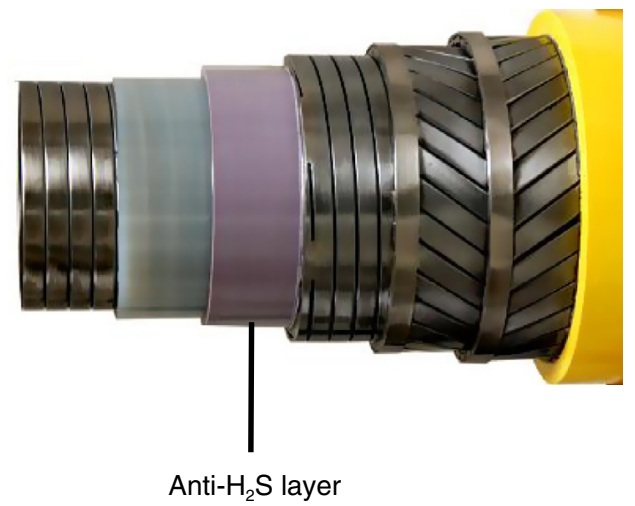

Figure 2

Position of the anti- $\mathrm{H}_{2} \mathrm{~S}$ layer in a flexible pipe. every flexible pipe takes into account this permeation phenomenon using a dedicated fluid permeation model [13]. This model enables one to predict the partial pressure of $\mathrm{H}_{2} \mathrm{~S}$ in the annulus based on the operating conditions of the structure. This partial pressure of $\mathrm{H}_{2} \mathrm{~S}$ is then taken into account in order to select the appropriate steel grade for the vault and armor layers. Considering the permeation phenomenon with time in the pressure sheath, current operating conditions lead more and more frequently to sour service conditions in the annulus after several months of operation.

The objective of the anti- $\mathrm{H}_{2} \mathrm{~S}$ layer new material is to avoid $\mathrm{H}_{2} \mathrm{~S}$ from reaching the structural steel layers during the whole service life of the pipe and hence to place the steel layers in a sweet service environment.

We chose to develop a material based on a polymer matrix which can replace or be extruded on the existing polymer pressure sheath. The target of this new sheath is to neutralize $\mathrm{H}_{2} \mathrm{~S}$ during its diffusion in the sheath. The neutralization is ensured by chemical reactions on reactive components that are dispersed in the polymer matrix. This is a reactive barrier polymer material. To ensure a $\mathrm{H}_{2} \mathrm{~S}$-free annulus, a layer of this material can be placed between the pressure sheath and the annulus (Fig. 2).

This paper illustrates the development of a barrier polymer material for flexible pipe applications: from the formulation of the reactive material, through the development of a dedicated multiphysics model, to qualification in sour service conditions.

The selection of raw materials is described in the first section of this paper. The selection is based on both accurate requirements for their use in a flexible pipe and expected performances in a sour service environment over a long period of time. In Section 2, the laboratory qualification of the material is described, as well as the experimental techniques used to qualify the behavior of the material and build the material database. In Section 3, the development of the dedicated multiphysics model is presented. Finally, the qualification of both the material and the model is performed thanks to middle-scale and full-scale tests conducted in representative sour service conditions.

\section{SELECTION OF RAW MATERIALS AND FORMULATION}

The raw material selection is based on both accurate requirements for their use in a flexible pipe and expected performances in a sour service environment.

The main components of the reactive material are the polymer matrix and the reactive components. The challenge consists of successfully developing the composite material, based on the mix of matrix and reactive components, knowing that it must meet several strict requirements to satisfy the application.

\subsection{Polymer Matrix Selection}

Requirements for the use of a polymer material as a sheath in a flexible pipe include several criteria, amongst which mechanical properties, durability in service conditions and transport properties are to be considered.

Each flexible pipe structure is designed for a given field, depending on several parameters such as temperature and pressure of the production fluid, $\mathrm{H}_{2} \mathrm{~S}$ and $\mathrm{CO}_{2}$ contents, water depth, etc.

For mechanical and chemical stability considerations, three categories of thermoplastic polymers are commonly 
used for the pressure sheath: PolyEthylene (PE), PolyAmide (PA) and PolyVinylidene DiFluoride (PVDF). The selection of the polymer during the design of a flexible pipe is strongly dependent on the temperature of the production fluid.

Diffusion mechanisms are temperature-dependent and roughly obey Fick's law [14]. Permeability characterizes the ability of a chemical species (such as $\mathrm{H}_{2} \mathrm{O}, \mathrm{H}_{2} \mathrm{~S}, \mathrm{CH}_{4}$ and $\mathrm{CO}_{2}$ ), to be transported through a polymer, and depends on the interaction between the polymer and the chemical species (the solute). Hence, it is an intrinsic property of the polymer - solute couple. The driving force for diffusion of solute in the polymer is the spatial difference in chemical activity of the solute in the polymer (Sect. 3).

Permeability is the product of the diffusion coefficient of the solute in the polymer, by the solubility of the solute in the polymer [11-14]. In a first approximation, for a given polymer - solute couple, both the diffusion coefficient and solubility value can be considered as temperature-dependent only. Their evolution as a function of temperature usually follows Arrhenius' law [11-14], but one must keep in mind that they can be pressure-dependent or depend on other solute contents [15-17]. In this case, mixture laws exist to describe the interaction between all solutes and the polymer [18-22].

A first generation of anti- $\mathrm{H}_{2} \mathrm{~S}$ material has been developed based on a polyethylene matrix to be used for temperatures up to $70^{\circ} \mathrm{C}$. This paper will mainly be dedicated to the presentation of the qualification work performed on this first generation of anti- $\mathrm{H}_{2} \mathrm{~S}$ material.

\subsection{Reactive Component Selection}

The barrier function of the material is provided by the presence of reactive components added to the matrix. As previously said, we focused on the neutralization of $\mathrm{H}_{2} \mathrm{~S}$ in contact with the reactive fillers, during its diffusion within the composite material. The objective is to ensure a $\mathrm{H}_{2} \mathrm{~S}$-free annulus during the service life of the flexible pipe (20 years generally). For this reason, we have to select highly reactive components so as to minimize the ratio of $\mathrm{H}_{2} \mathrm{~S}$ diffusion in the matrix to $\mathrm{H}_{2} \mathrm{~S}$ reaction with the active components.

One characteristic of transition metal oxides is their propensity to react with acid species. The catalytic activity of many metal oxides depends on both the strength and the amount of Lewis and Brønsted acid-base sites. Cationic metal sites act as Lewis acids while anionic oxygen sites act as Lewis bases. Concerning surface hydroxyl groups, they are able to serve as Brønsted acid or base sites as they are able to give up or accept a proton [23].

Metal oxide can exist in many forms (size, shape, etc.), so the selection of a metal oxide for our application is challenging: it is based on several technical parameters such as reactivity and the chemical nature of the reaction products, but also toxicity, cost, reliability of supply, etc. Experimental characterization of some metal oxides and thermodynamic calculation will help the selection.

The chemical reaction taking place in the anti- $\mathrm{H}_{2} \mathrm{~S}$ material is a reaction of a gas species on a solid particle. Gas-Solid reactions are known to be particle size- and shape-dependent (Sect. 3.2). Because the metal oxide surface is directly accessible, surface reactions are quicker than volume reactions. Now, considering the metal oxide as a spherical particle, the smaller the particle, the higher the ratio of its surface to its volume, and so the higher the relative amount of rapid surface reactions. This notion is related to the specific surface of the particle $\left(\mathrm{m}^{2} / \mathrm{g}\right)$, which is defined as the average ratio of the surface of particles to their weight.

So, to promote rapid reactions on surface particles, rather than reactions in the volume of the particle, the smallest particles may be selected.

Based on both experimental sulfidation test results and thermodynamic calculations, zinc oxide $(\mathrm{ZnO})$ and iron (III) oxide $\left(\mathrm{Fe}_{2} \mathrm{O}_{3}\right)$ were found to be among the best candidates for the application.

Chemical reactions involved in the composite material are:

$$
\begin{gathered}
\mathrm{ZnO}+\mathrm{H}_{2} \mathrm{~S}=\mathrm{ZnS}+\mathrm{H}_{2} \mathrm{O} \\
\mathrm{Fe}_{2} \mathrm{O}_{3}+4 \mathrm{H}_{2} \mathrm{~S}=2 \mathrm{FeS}_{2}+3 \mathrm{H}_{2} \mathrm{O}+\mathrm{H}_{2}
\end{gathered}
$$

The amount of metal oxide introduced into the material is determined according to the target performance while maintaining both appropriate mechanical properties of the material for the application, and good extrudability and processing properties.

\subsection{Compounding}

In order to qualify anti- $\mathrm{H}_{2} \mathrm{~S}$ compositions, a laboratory study was carried out. Lab-scale formulations were performed and composites characterized. Thermoplastic polymer/metal oxide composites were prepared by melt compounding using a Thermo ${ }^{\circledR}$ PTW 16/25 XL corotating twin screw extruder. A volumetric screw feeder is used for the polymer. A gravimetric screw feeder allowed bringing the metal oxide inside the polymer matrix.

Different parameters were studied, such as the nature and the grade of the thermoplastic matrix and the nature, grade and weight fraction of the metal oxide. Based on this study some formulations were selected toward their $\mathrm{H}_{2} \mathrm{~S}$-barrier properties and their mechanical behavior. This paper deals with the material called PEZnO, composed of a thermoplastic matrix in $\mathrm{PE}$ compounded with $\mathrm{ZnO}$ and $\mathrm{Fe}_{2} \mathrm{O}_{3}$. Both oxides will react with $\mathrm{H}_{2} \mathrm{~S}$. The reaction with $\mathrm{ZnO}$ will be 
responsible for the efficiency of the system, whereas $\mathrm{Fe}_{2} \mathrm{O}_{3}$, which gives its initial purple color to the material, will be used as a visual tracer of the reaction with $\mathrm{H}_{2} \mathrm{~S}$.

\section{LABORATORY-SCALE QUALIFICATION AND DATABASE ACQUISITION FOR MODELING}

\subsection{Objective of the Laboratory-Scale Qualification}

In flexible pipeline applications, the aim of anti- $\mathrm{H}_{2} \mathrm{~S}$ materials is to ensure that no $\mathrm{H}_{2} \mathrm{~S}$ crosses the anti- $\mathrm{H}_{2} \mathrm{~S}$ sheath during the whole service life of the pipe. To achieve this goal, we need to understand the mechanisms that take place in the material in order to develop a predictive physical model.

In the presence of $\mathrm{H}_{2} \mathrm{~S}$, anti- $\mathrm{H}_{2} \mathrm{~S}$ material is the place of a competition between two mechanisms: diffusion of $\mathrm{H}_{2} \mathrm{~S}$ in the polymer matrix, and chemical reaction of $\mathrm{H}_{2} \mathrm{~S}$ with metal oxide particles. These two mechanisms have opposite effects on $\mathrm{H}_{2} \mathrm{~S}$ advance in the composite material.

As illustrated in Figure 3, the competition between $\mathrm{H}_{2} \mathrm{~S}$ diffusion in the matrix and $\mathrm{H}_{2} \mathrm{~S}$ reaction with particles forms a reaction area within the anti- $\mathrm{H}_{2} \mathrm{~S}$ layer. This reaction area will progress inside the material. For a given diffusion coefficient of $\mathrm{H}_{2} \mathrm{~S}$ in the polymer matrix, the more reactive the particle, the smaller the reaction area.

To understand the behavior of such a material on the laboratory scale, we need to determine:

- the position of the $\mathrm{H}_{2} \mathrm{~S}$ front with time;

- the degree of conversion in the material: upstream of the reaction front to characterize the reactivity of the material,

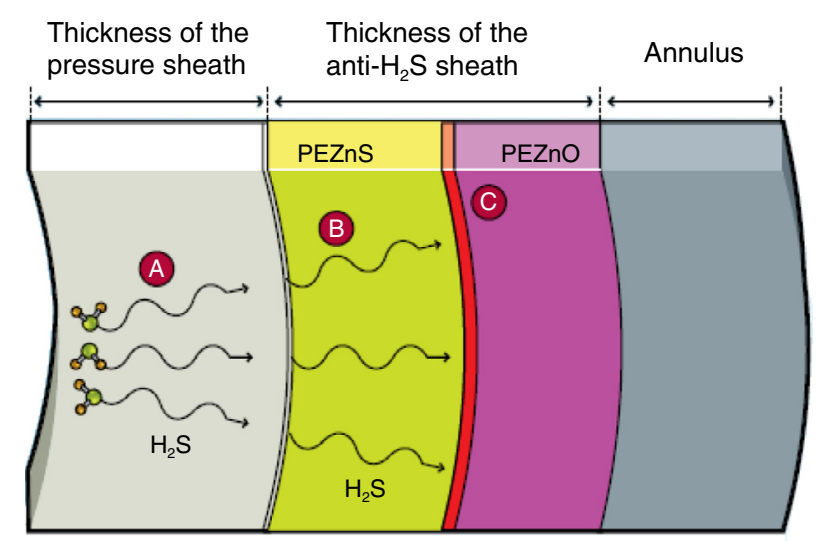

Figure 3

Progression of the reaction front in the anti- $\mathrm{H}_{2} \mathrm{~S}$ layer during time. Step A: $\mathrm{H}_{2} \mathrm{~S}$ transport through pressure sheath. Step B: $\mathrm{H}_{2} \mathrm{~S}$ transport through PEZnS (anti- $\mathrm{H}_{2} \mathrm{~S}$ material already reacted). Step $\mathrm{C}: \mathrm{H}_{2} \mathrm{~S}$ reaction with $\mathrm{ZnO}$ (reaction area in red). and downstream of the reaction front to ensure that no $\mathrm{H}_{2} \mathrm{~S}$ has passed and reacted beyond this point;

- the $\mathrm{H}_{2} \mathrm{~S}$ concentration in the downstream environment so as to determine, for given experimental parameters, the time after which $\mathrm{H}_{2} \mathrm{~S}$ will finally cross the material. This time is commonly called the breakthrough time.

Two main kinds of tests can be performed to produce data required to understand and characterize the behavior of anti$\mathrm{H}_{2} \mathrm{~S}$ materials:

- breakthrough test: based on permeability test principles [12], this test consists of measuring the time after which $\mathrm{H}_{2} \mathrm{~S}$ is detected by Gas Chromatography (GC) downstream of a sample, while applying upstream an environment containing $\mathrm{H}_{2} \mathrm{~S}$. This breakthrough time fully characterizes the behavior of the material since the test conditions are very similar to the application. Moreover, several analyses can be performed on the sample after the breakthrough test: degree of conversion measurements in the thickness, position of the reaction front at breakthrough time, etc. Nevertheless, this kind of test can be very long since the breakthrough time can be equal to several tens or even hundreds of days. So, we will favor the performing of this kind of test during the validation step on middle-scale and full-scale representative structures;

- immersion test: coupons are placed in a vessel in which they are immersed in an environment containing pure $\mathrm{H}_{2} \mathrm{~S}$ or a gas mixture including $\mathrm{H}_{2} \mathrm{~S}$. Pressure and temperature are adapted to perform the tests in appropriate conditions to build the database. Typically, the $\mathrm{H}_{2} \mathrm{~S}$ partial pressure during the test is less than 6 bar, and the temperature is between $20^{\circ} \mathrm{C}$ and $60^{\circ} \mathrm{C}$. Samples are collected after several intervals of time in order to follow the position of the $\mathrm{H}_{2} \mathrm{~S}$ front, degree of conversion, weight evolution, etc.

Mainly pure $\mathrm{H}_{2} \mathrm{~S}$ tests were performed to produce the database needed for the development and identification of the model. These conditions have the effect of accelerating the mechanisms in the material. Tests were performed at several temperatures representative of the application in order to be able, afterward, to differentiate the temperature dependence of each mechanism. The pertinence of this approach will be confirmed by small-scale and full-scale tests performed in more representative conditions of the application (low partial pressure of $\mathrm{H}_{2} \mathrm{~S}$, for instance).

\subsection{Analytical Techniques Used for Data Determination}

To produce the database, we focus on $\mathrm{H}_{2} \mathrm{~S}$ front progression and measurements of the degree of conversion, both measured in the thickness of the material. To this end, immersion tests were performed in several conditions of temperature and $\mathrm{H}_{2} \mathrm{~S}$ partial pressures. During these tests, samples were 
placed in a pressure vessel which was then filled with the test gas at the test temperature and pressure. To follow the mechanisms with time, samples were then removed at regular intervals of time, and subsequently cut in half along the diameter for analyses.

\subsubsection{Techniques for $\mathrm{H}_{2} \mathrm{~S}$ Front Progression Measurement}

Two main techniques were developed to follow the reaction front progression:

- optical microscopy: the PEZnO material contains $\mathrm{Fe}_{2} \mathrm{O}_{3}$, which is responsible for the change in color of the material after its reaction with $\mathrm{H}_{2} \mathrm{~S}$. A microscope equipped with a measuring plate allows one to measure the position of the interface between the already reacted material (gray: $\mathrm{FeS}_{2}$ ) and the non-reacted material (purple: $\mathrm{Fe}_{2} \mathrm{O}_{3}$ ). A NIKON Measurescope 10 is used. Its theoretical accuracy is $1 \mu \mathrm{m}$. The distance from the surface of the sample to this interface corresponds to the progression of $\mathrm{H}_{2} \mathrm{~S}$ within the material during the time of the test (Fig. 4);

- Electron Probe Micro-Analysis (EPMA): to verify that the change in color within the material does correspond exactly to $\mathrm{H}_{2} \mathrm{~S}$ progression in the material during the test, a CAMECA SX 100 EPMA is used to locate the position of the reaction front and to ensure that no $\mathrm{ZnO}$ has reacted after the interface. Figure 5 illustrates, for several immersion times in given immersion conditions, the good agreement obtained between optical and EPMA progression front measurements up to several millimeters. In addition, permeability tests and both middle-scale and full-scale tests performed in permeability configuration and monitored by gas chromatography never revealed any breakthrough of $\mathrm{H}_{2} \mathrm{~S}$ as long as the reaction front did not reach the downstream side of the material. SRA microGC are used on test units.

Optical microscopy measurements are performed to follow routine tests on coupons, whereas EPMA measurements are used to confirm front locations on chosen samples (middle-scale and full-scale structures, for instance). Taking

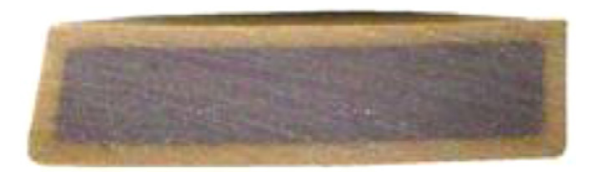

Figure 4

Anti- $\mathrm{H}_{2} \mathrm{~S}$ coupon cut in half along the diameter after a $\mathrm{H}_{2} \mathrm{~S}$ exposure test in immersion configuration. Gray area (border): $\mathrm{H}_{2} \mathrm{~S}$ progression area (the material has reacted with $\mathrm{H}_{2} \mathrm{~S}$ ). Purple area (core): unreacted material (absence of $\mathrm{H}_{2} \mathrm{~S}$ ).

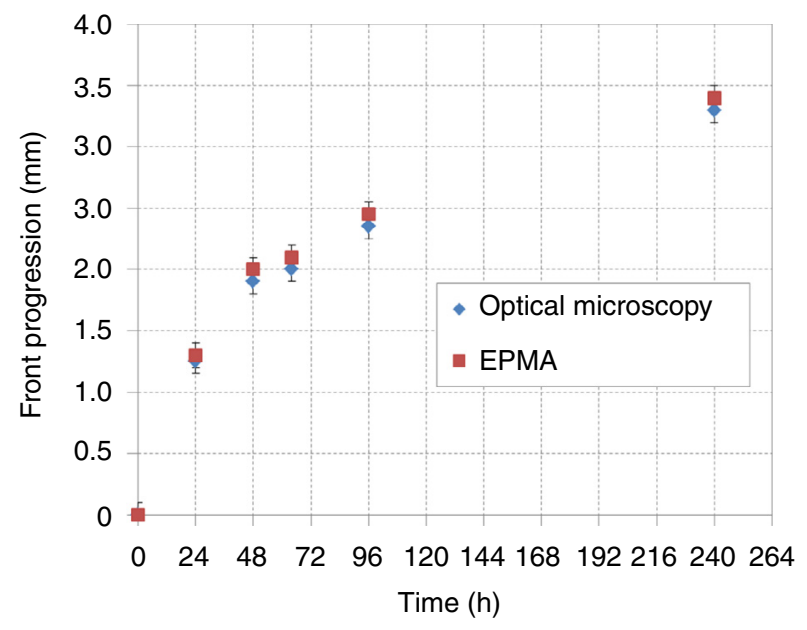

Figure 5

Comparison between optical microscopy and EPMA front progression measurements.

into account all sources of uncertainty, the expected accuracy of both these techniques is of the order of $0.1 \mathrm{~mm}$.

\subsubsection{Techniques for Degree of Conversion Measurement}

Several methods have been developed to measure the degree of conversion of the material. Depending on the technique employed, this measurement can be performed on a global scale for the whole sample or on a more local scale at several points of the front progression:

- weight uptake: global information for the whole sample. The weight uptake relies on the chemical transformation of the metal oxide in sulfide compounds during operation. This measurement allows one, for instance, to follow the progress of a test or to ensure that a sample is completely converted into sulfur compounds;

- Thermo-Gravimetric Analysis (TGA): TGA can be used to measure the weight loss which characterizes the oxidation of $\mathrm{ZnS}$ (or $\mathrm{FeS}_{2}$ ) in $\mathrm{ZnO}$ (or $\mathrm{Fe}_{2} \mathrm{O}_{3}$ ) at very high temperature in the presence of oxygen, and hence to know the relative content of $\mathrm{ZnS}$ in the material;

- Elemental Analysis (EA): EA is used to measure the sulfur content in samples. Knowing the initial composition of the material, this measurement can be correlated with the degree of conversion of the reaction. For instance, samples can be cut into successive thin strips (with a microtome) parallel to the front advance in order to know the evolution of the degree of conversion;

- EPMA: already used to measure the position of the reaction front within the material, this technique can rate the degree of conversion at every point of the analyzed 
surface. To do this, a dedicated methodology has been developed in order to compute the quantitative degree of conversion from Wavelength Dispersive Spectroscopy (WDS) spectra obtained on PEZnO samples (Sect. 3.3.2).

\section{DEVELOPMENT OF A DEDICATED MULTIPHYSICS DIFFUSION-REACTION MODEL}

At the time of an anti- $\mathrm{H}_{2} \mathrm{~S}$ flexible pipe design, the initial thickness of the anti- $\mathrm{H}_{2} \mathrm{~S}$ layer will be chosen in order to ensure that the reaction front does not cross the entire anti$\mathrm{H}_{2} \mathrm{~S}$ layer to reach the annulus before the end of the lifetime of the pipe. As a consequence, the model will be developed to be able to predict the position of the reaction front, for all testing conditions.

The first step consists of identifying the right physics, based on the comprehension of the mechanisms that take place in the material and experimental characterizations described in Section 2. Then, parameter identification will be performed on the database.

\subsection{Diffusion Mechanisms in the Matrix: The Driving Force of the Gas Advance in the Material}

As for all polymeric materials, chemical species can permeate through the material. So, at the surface of the material in contact with $\mathrm{H}_{2} \mathrm{~S}, \mathrm{H}_{2} \mathrm{~S}$ solubilizes and penetrates into the material then slowly diffuses across the material thickness to the other side.

\subsubsection{Diffusion Coefficient, $D$}

The driving force behind the progression of one species in the material is the gradient of the chemical potential of this particular species between the upstream and downstream sides of the material. The diffusion coefficient, $D$, stands for the intensity of this driving force and hence reflects the speed of the molecules under the effect of the chemical potential gradient between the upstream and downstream sides of the material. $D$ is the kinetic component of the transport.

So, considering a one-way flow of particles along the $x$ axis, the elementary flow of particles through a section, $J\left[\mathrm{~mol} /\left(\mathrm{m}^{2} / \mathrm{s}\right)\right]$, is linked to the local concentration gradient of gas through the diffusion coefficient $D$. This dependence is expressed by Fick's first law [14]:

$$
J_{x}(x, t)=-D \frac{\partial c}{\partial x}(x, t)
$$

Mass balance implies that the evolution of the gas concentration in a given section is equal to the amount of incoming molecules less the amount of outgoing molecules. This balance is expressed by Fick's second law [14]. For a unidirectional flow:

$$
\frac{\partial c}{\partial t}(x, t)=-\frac{\partial J_{x}}{\partial x}(x, t)=\frac{\partial D}{\partial x} \frac{\partial c}{\partial x}(x, t)+D \frac{\partial^{2} C}{\partial x^{2}}(\mathrm{x}, \mathrm{t})
$$

When the diffusion coefficient, $D$, can be considered as independent of the gas concentration, $c$, of the position of the molecule in the material, $x$, and of time, $t$, this expression leads to the fundamental equation of diffusion [14]:

$$
\frac{\partial c}{\partial t}(x, t)=D \frac{\partial^{2} C}{\partial x^{2}}(x, t)
$$

The diffusion coefficient, $D$, is generally expressed in $\mathrm{m}^{2} \cdot \mathrm{s}^{-1}$.

\subsubsection{Solubility Coefficient, $S$}

The solubility coefficient is the thermodynamic component of the transport mechanism in polymer: it characterizes the propensity of a given chemical species to solubilize into the polymer. So, at balance at a given pressure (in bar for instance), the solubility represents the amount of gas (in mol, for instance) inside a given volume of the material (one cubic meter, for instance). Consequently, the solubility coefficient can be expressed in mol.m $\mathrm{m}^{-3} \cdot \mathrm{bar}^{-1}$.

The local concentration of gas solubilized in the polymer, $c$, can be connected to the local partial pressure of the gas, $P$, by the following equation:

$$
c=S(c) \cdot P
$$

where $S(c)$ is the solubility coefficient, which depends on the temperature and can vary with $c$ (or $P$ ).

If there is no interaction between the diffusing molecule and the polymer, the above equation can be linked to Henry's Law, which suggests, for a given temperature, a linear variation of the concentration, $c$, with the pressure, $P[11,12,14]$. In this case, the coefficient solubility is equal to the Henry constant.

Formally, the use of Henry's law requires the environment to meet several requirements: no synergistic effects between the gases, presence of only low condensable gas $\left(\mathrm{N}_{2}, \mathrm{O}_{2}, \mathrm{H}_{2}\right.$, $\mathrm{CH}_{4}$, etc.), intermediate pressure (typically $<100$ bar), and polymer above its glass transition temperature. For higher pressures or more condensable gas $\left(\mathrm{CO}_{2}, \mathrm{H}_{2} \mathrm{~S}\right)$, it is necessary to take into account condensation and interactions between the gases of different chemical nature. As a consequence, in gas mixtures containing a few percent of $\mathrm{H}_{2} \mathrm{~S}$ in both $\mathrm{CO}_{2}$ and $\mathrm{CH}_{4}$, the partial pressure of $\mathrm{H}_{2} \mathrm{~S}$ is no longer representative of the activity of this gas. In this case, it is essential to use the fugacity of $\mathrm{H}_{2} \mathrm{~S}$ which is calculated based on the thermodynamic data of all gas species present in the environment [15-22]. 


\subsection{Chemical Reaction on the Particles: An Obstacle to Gas Progression in the Material}

The chemical reactions take place on metal oxide particles, themselves embedded in a polymer. As a result, the gas amount around each reactive particle is a function of the diffusion mechanism described in Section 3.1. Nevertheless, on the material scale, these two mechanisms are interdependent since the local concentration of $\mathrm{H}_{2} \mathrm{~S}$ depends on both $\mathrm{H}_{2} \mathrm{~S}$ transport by diffusion and its neutralization rate on particles. So, to model the behavior of such a material, i.e. the competition between diffusion and reaction, we need to develop a model in which these two physical mechanisms are coupled. To do that, the Finite Element Method (FEM) was selected especially because of the flexibility in boundary condition definition.

In the case of a chemical reaction of a fluid on a reactive solid, the properties of the solid can be a major point of consideration, because the global kinetics of the reaction can greatly depend on the morphology of the solid (size, shape, porosity rate, etc.). As reported in the literature among fluidparticle reaction theories [24-27], one model (and several variants) has been successfully used: the Shrinking Core Model (SCM), originally developed by Yagi and Kunii $[24,25]$. On the scale of one particle (Fig. 6), this model suggests that the chemical reaction first occurs at the outer skin of the particle and then moves into the solid, leaving behind a completely converted and inert solid, commonly called "ash". So, simultaneously with the reaction front advance inside the particle, the unreacted core of the particle shrinks in size. On the scale of the particle, this mechanism leads

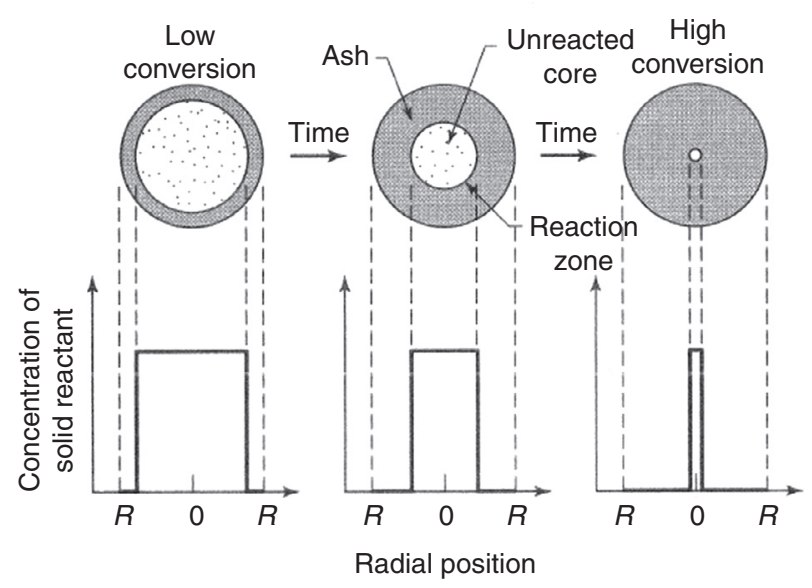

Figure 6

SCM - Evolution of the reaction front inside the reactive particle with time (from [26]). to typical evolutions of the degree of conversion, based on the combination of all individual mechanisms of this fluidparticle reaction.

The reaction rate is based on several mechanisms occurring successively at different levels within the particle, each mechanism having its own kinetics. Resistances to the reaction induced by each of these steps are often very different from each other. Since these steps occur successively, it is therefore possible to consider only the one(s) which control(s) the reaction rate. Indeed, the slowest mechanism imposes its rate on other mechanisms. This is the ratelimiting step. Formally, the gas-solid reaction can be divided into five successive steps (Fig. 7) [26, 27]:

- diffusion of $\mathrm{H}_{2} \mathrm{~S}$ through the polymer-particle interface: corresponds to the diffusion of $\mathrm{H}_{2} \mathrm{~S}$ across the boundary layer surrounding the particle. In the present case, this boundary layer is the interface between the polymer and the particle. This mechanism, also called transfer resistance, corresponds to the ability of the gas to get out of the polymer to enter the particle. The mass transfer coefficient between the polymer and the particle, $k_{D}$, is by definition equal to $D_{\mathrm{PEZnS}} / R_{0}[26,27]$ : the ratio of $\mathrm{H}_{2} \mathrm{~S}$ diffusion in the composite material divided by the radius of the particles;

- diffusion of $\mathrm{H}_{2} \mathrm{~S}$ in the already reacted part of the particle: corresponds to the penetration of $\mathrm{H}_{2} \mathrm{~S}$ into the particle and its diffusion through the $\mathrm{ZnS}$ layer to the reaction front,

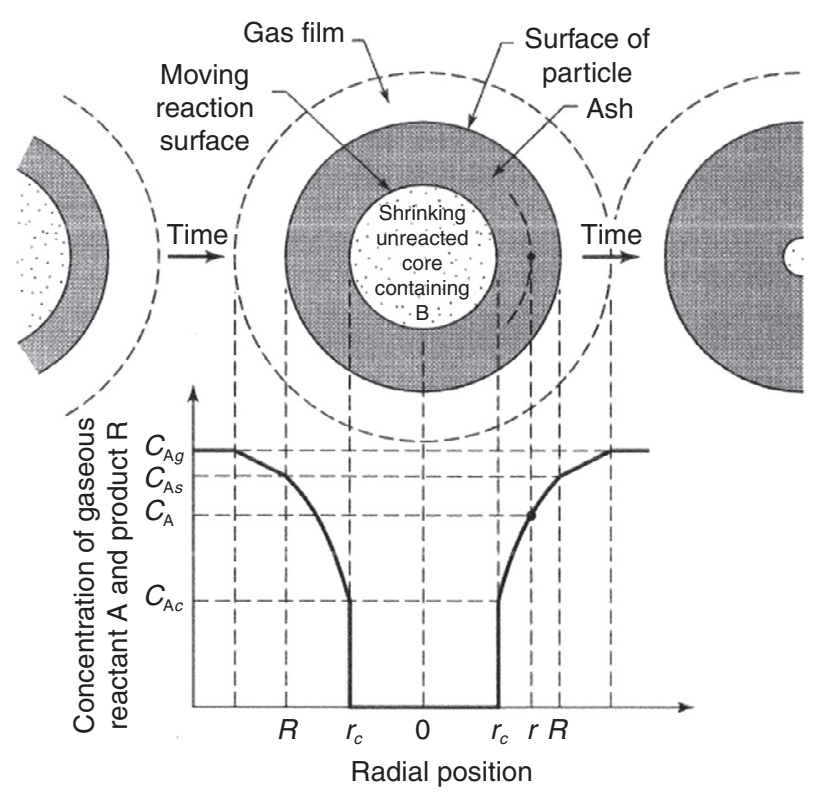

Figure 7

Representation of the successive steps of the SCM (from [26]). 
that is to say, the surface of the unreacted core. This mechanism reveals the ability of $\mathrm{H}_{2} \mathrm{~S}$ to diffuse through the $\mathrm{ZnS}$ layer. $D_{\mathrm{ZnS}}$ is the diffusion coefficient of $\mathrm{H}_{2} \mathrm{~S}$ in $\mathrm{ZnS}$, and $R_{0}$ is the mean radius of $\mathrm{ZnO}$ particles;

- chemical reaction at the surface of the unreacted core. During this step, $\mathrm{H}_{2} \mathrm{~S}$ is transformed into $\mathrm{H}_{2} \mathrm{O}$ and $\mathrm{ZnO}$ is transformed into $\mathrm{ZnS}$. The reaction rate constant is $k_{c}$;

- diffusion of reaction products $\left(\mathrm{H}_{2} \mathrm{O}\right)$ in the "ash" back into the exterior of the particle. In our case, we consider that the diffusion of water into the $\mathrm{ZnS}$ does not limit the reaction kinetics. According to our experimental results, the presence of water would even tend to favor the global reaction;

- transfer of reaction products $\left(\mathrm{H}_{2} \mathrm{O}\right)$ back into the polymer through the interface. In our case, we consider that the diffusion of water back into the external environment does not limit the reaction. As for the previous point, according to our experimental results the presence of water would even tend to favor the global reaction.

\subsection{KilHyS Parameter Identification and Results}

The model developed to describe the behavior of the reactive material was named KilHyS, for Kill Hydrogen Sulfide. This model is based on the mechanisms and parameters described in Sections 3.1 and 3.2.

KilHyS parameter identification is based on immersion test results. These tests were mainly performed with pure $\mathrm{H}_{2} \mathrm{~S}$ in order to accelerate the mechanisms in the material, but some gas mixture or multiphasic condition tests were also performed. The relevance of this approach is confirmed by larger-scale tests in more representative conditions of the application described in Section 4.

Tests were carried out at several temperatures representative of the application in order to be able to differentiate the temperature dependence of each mechanism.

At regular intervals of time (from a few days to more than one year), samples are removed from the pressure vessel and cut into two parts in order to identify both front progression and front shape by optical and electron microscopy.

\subsubsection{Identification of Transport Parameters}

Except when components promote an increase in tortuosity in the material (that is to say, a geometrical lengthening of the diffusion path), their incorporation in a polymer generally leads to an increase in the permeability of the composite material. This rise can be the consequence of an increase in the diffusion coefficient, $D$, and/or the solubility, $S$. Greater free volume and preferential path formation are potential causes of a composite permeability increase. Thus, transport parameters of the anti- $\mathrm{H}_{2} \mathrm{~S}$ material must not be determined on the matrix, but on the composite material.

\subsubsection{Identification of the Gas-Solid Reaction Parameters}

The main method used to identify the diffusion coefficient of $\mathrm{H}_{2} \mathrm{~S}$ in $\mathrm{ZnS}, D_{\mathrm{ZnS}}$ and the reaction rate constant of $\mathrm{H}_{2} \mathrm{~S}$ with $\mathrm{ZnO}, k_{c}$, is EPMA along the reaction front advance, in the thickness of the material. Knowing the transport parameters in the material, $D_{\mathrm{PEZnS}}$ and $S_{\mathrm{PEZnS}}$, then the diffusion coefficient of $\mathrm{H}_{2} \mathrm{~S}$ in $\mathrm{ZnS}$ and the reaction rate constant of reaction of $\mathrm{H}_{2} \mathrm{~S}$ with $\mathrm{ZnO}$ can be identified thanks to degree of conversion measurements performed in the thickness of the specimen taken after several immersion times in $\mathrm{H}_{2} \mathrm{~S}$.

As an example, Figure 8 represents the experimental degree of conversion (dots) measured by EPMA after 3 duration times in given test conditions and the corresponding KilHyS calculations (solid curves). The three specimens analyzed in this figure experienced different aging times in the same aging conditions. We can see good agreement on both the front position and front shape of the curves. EPMA precision is limited by the heterogeneity of the material on the scale of the electron beam. The expected accuracy on the determination of the degree of conversion is of the order of $10 \%$ of the measured value.

\subsubsection{Identification Assessment}

A total of more than 50 tests were performed to establish the database. These tests were performed in different conditions:

- temperatures ranging from $38^{\circ} \mathrm{C}$ to $71^{\circ} \mathrm{C}$;

- $\mathrm{H}_{2} \mathrm{~S}$ partial pressures ranging from 26 mbar to $5.8 \mathrm{bar}$;

- nature of the fluid: pure $\mathrm{H}_{2} \mathrm{~S}$, gas mixture $\left(\mathrm{H}_{2} \mathrm{~S}_{-} \mathrm{CO}_{2}\right.$ $\mathrm{CH}_{4}$ ), multiphase conditions (aqueous + gas).

The results of these tests, in terms of front advances, along with the results of the KilHyS model predictions, are

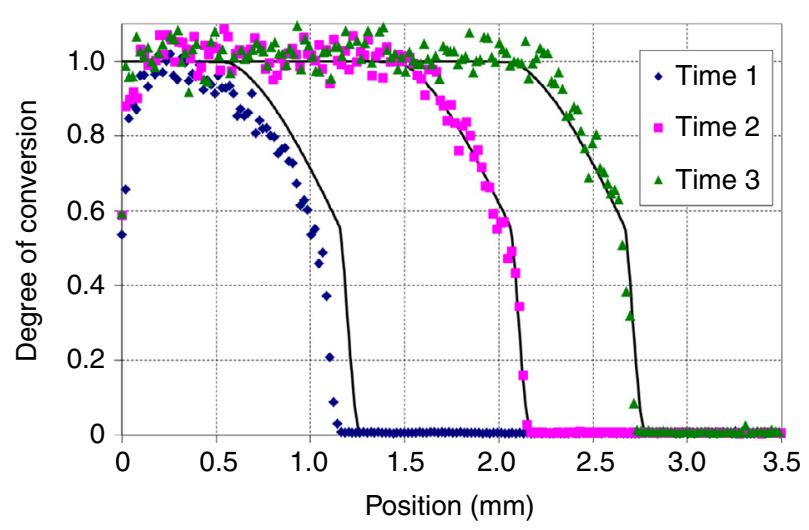

Figure 8

Experimental degrees of conversion (dots) and corresponding KilHyS calculations (solid curves) in the thickness of the material, from the surface to the core (Fig. 4). 
presented in Figure 9. Very good agreement between the database and the model is obtained.

Even if the aim of the identification step is to obtain a good fit between experimental data and numerical simulation, the fact that experimental data and numerical simulations are consistent in various experimental conditions of temperature, the pressure and nature of the fluid, and resulting in the determination of physical parameters that follow some Arrhenius laws, promotes the idea that the diffusionreaction mechanisms described in Sections 3.1 and 3.2, and present in the KilHyS model, correctly describe the experimental behavior of the anti- $\mathrm{H}_{2} \mathrm{~S}$ material. Described in the next section, the validation in representative environments of both the material and the model will confirm this choice of modeling.

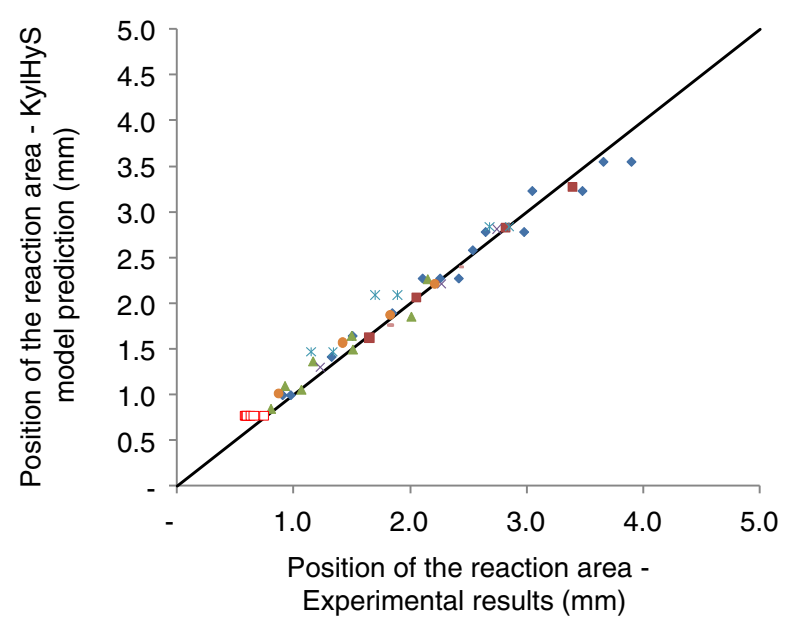

Figure 9

Assessment of the correlation between the experimental database and KilHyS prediction after the parameter identification. Each symbol stands for an experimental condition $\left(\mathrm{H}_{2} \mathrm{~S}\right.$ partial pressure, temperature).

a)

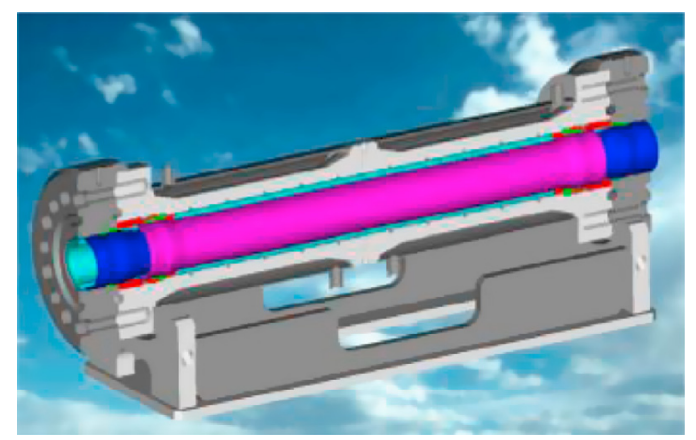

\section{QUALIFICATION OF BOTH THE MATERIAL AND THE MODEL ON STRUCTURES TESTED IN REPRESENTATIVE ENVIRONMENTS}

\subsection{Tests on Two-Layer Middle-Scale Tubes in Representative Conditions}

The main objectives of these tests on simplified structures are to validate:

- the anti- $\mathrm{H}_{2} \mathrm{~S}$ concept and model prediction in a two-layer axisymmetric configuration;

- model predictions in a system showing a temperature gradient;

- model predictions in more representative environments than during tests on material samples.

As presented in Figure 10, the two-layer configuration is composed of a tube of polyamide 11 (a pressure sheath material) surrounded by a tube of anti- $\mathrm{H}_{2} \mathrm{~S}$ material before sealing. The internal diameter is 3.5". A metallic piece with gaps, in contact with the outer surface of the anti- $\mathrm{H}_{2} \mathrm{~S}$ tube, simulates the geometry of the pressure vault. Test durations vary between 1 month and 4 months.

The progression of the reaction area in the anti- $\mathrm{H}_{2} \mathrm{~S}$ tube is measured after cutting the tube in several cross sections as shown in Figure 10b. The measurement is performed by using the color change induced by the reaction with $\mathrm{H}_{2} \mathrm{~S}$ and EPMA. The change in color is illustrated in Figure 11. The gray area corresponds to the bore side where the material has reacted with $\mathrm{H}_{2} \mathrm{~S}$. The purple area corresponds to the annulus side where the material is still in its initial state (unreacted with $\mathrm{H}_{2} \mathrm{~S}$ ).

Gas chromatography measurements [12] are also performed at regular intervals of time during these tests in order to monitor the composition of the gas permeating through the polymer materials and to verify that no $\mathrm{H}_{2} \mathrm{~S}$ is able to penetrate into the annulus.

b)

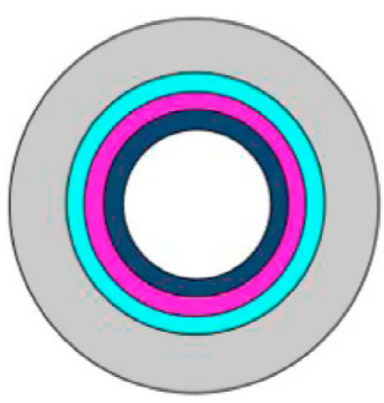

Rilsan P40TL tube

Anti- $\mathrm{H}_{2} \mathrm{~S}$ tube

Shell with gaps simulating pressure vault geometry

Middle-scale test cell

Figure 10

Two-layer middle-scale structure configuration. 


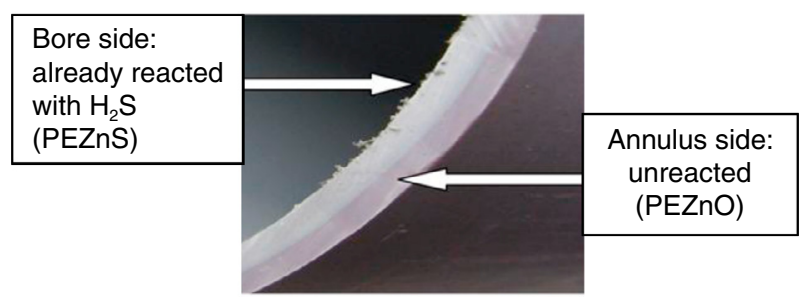

Figure 11

Change in color due to the reaction of $\mathrm{H}_{2} \mathrm{~S}$ in the anti- $\mathrm{H}_{2} \mathrm{~S}$ tube shown in Figure 10 (the total thickness of the tube is $4 \mathrm{~mm}$ ).

As presented in Figure 12, four tests have already been performed, some of them being as long as 120 days. These tests were performed using either pure $\mathrm{H}_{2} \mathrm{~S}$ or gas mixture $\mathrm{CH}_{4} / \mathrm{H}_{2} \mathrm{~S}$, in single-phase (gas) or multiphase conditions (ASTM Gasoil + gas mixture). Out of all tests performed in this configuration, the partial pressure of $\mathrm{H}_{2} \mathrm{~S}$ is of the order of 5 bar, for a total pressure from 50 bar to 110 bar. The temperature in the bore is $70^{\circ} \mathrm{C}$. Very good agreement between the experimental results and KilHyS model prediction is achieved. These results illustrate the ability of the model to describe the right physical mechanisms even in complex experimental conditions as long as each mechanism has been identified on samples.

We can note a lower progression of the experimental front in the oil phase than in the gas phase (test No. 4). We explain this observation by the delay induced by the solubilization of the gas in the oil phase before it can reach the polymer sheath, which is not taken into account by the model.

\subsection{Tests on Full-Scale Flexible Pipes in Static and Dynamic Conditions}

In addition to the tests performed in pressure vessels and on simplified bi-layer structures, full-scale tests on representative 4.8 " flexible pipes structures are ongoing in order to validate the concept on real flexible pipes. The 8 meter long structures were manufactured using Technip Le Trait (France) manufacturing unit industrial equipment. The overall duration of these tests is 2 years of effective testing with sampling of anti- $\mathrm{H}_{2} \mathrm{~S}$ samples of the structure every 6 months.

These full-scale tests are performed on seven representative structures: one dynamic prototype, one static prototype, and five samples of structures. The objectives of these tests are to demonstrate:

- the efficiency of the material on a full-scale structure in both dynamic and static configurations;

- the mechanical performance of the anti- $\mathrm{H}_{2} \mathrm{~S}$ material both before reaction and after reaction with $\mathrm{H}_{2} \mathrm{~S}$.

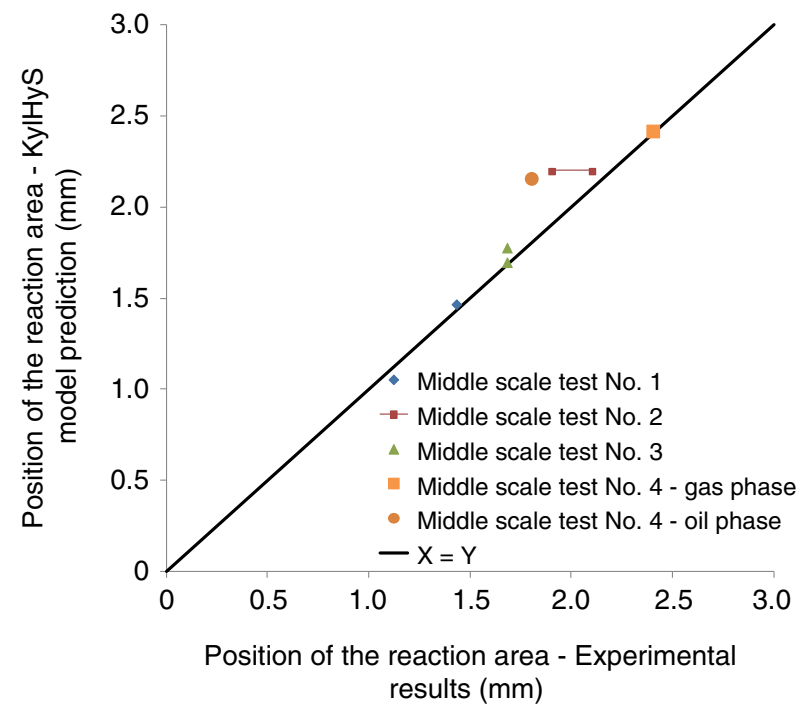

Figure 12

Assessment of the correlation between middle-scale experimental data and KilHyS predictions. The position of the reaction area corresponds to the front progression in the anti- $\mathrm{H}_{2} \mathrm{~S}$ layer.

Each test structure contains a $\mathrm{PEZnO}$ anti- $\mathrm{H}_{2} \mathrm{~S}$ layer. The structures are exposed to a gas mixture containing both $\mathrm{CO}_{2}$ and $\mathrm{H}_{2} \mathrm{~S}$ in $\mathrm{CH}_{4}$. The molar composition of the gas mixture is: $\mathrm{H}_{2} \mathrm{~S}=1.5 \%, \mathrm{CO}_{2}=5.0 \%, \mathrm{CH}_{4}=93.5 \%$. The pressure of the gas mixture in the bore is 200 bar, the temperature in the bore is $80^{\circ} \mathrm{C}$.

The testing devices are located at IFP Energies nouvelles in Solaize near Lyon (France), where two units are designed to receive prototypes up to 10 meter long and test them in severe conditions. One unit is dedicated to testing static structures, whereas the second is dedicated to testing structures in dynamic conditions: a hydraulic actuator is used to perform representative mechanical solicitation on the structure on demand (in bending, tension, etc.). In the present case, as shown in Figure 13, the dynamic prototype is slung up in bending between a fixed trolley and a mobile trolley so that the anti- $\mathrm{H}_{2} \mathrm{~S}$ layer of the structure exhibits a given radius of curvature. Curvature cycling is then performed around this mean value. The surface of the prototype is cooled by closed-loop refrigerated water (not visible in Fig. 13).

Not all the prototypes will be tested during the full 2 years. Every 6 months of effective testing, a sample of the structure, as shown in Figure 14, will be removed from the test area in order to be thoroughly dissected. This way it will be possible to follow the position of the reaction area with aging time.

To date:

- 450000 cycles have been performed on the dynamic prototype; 


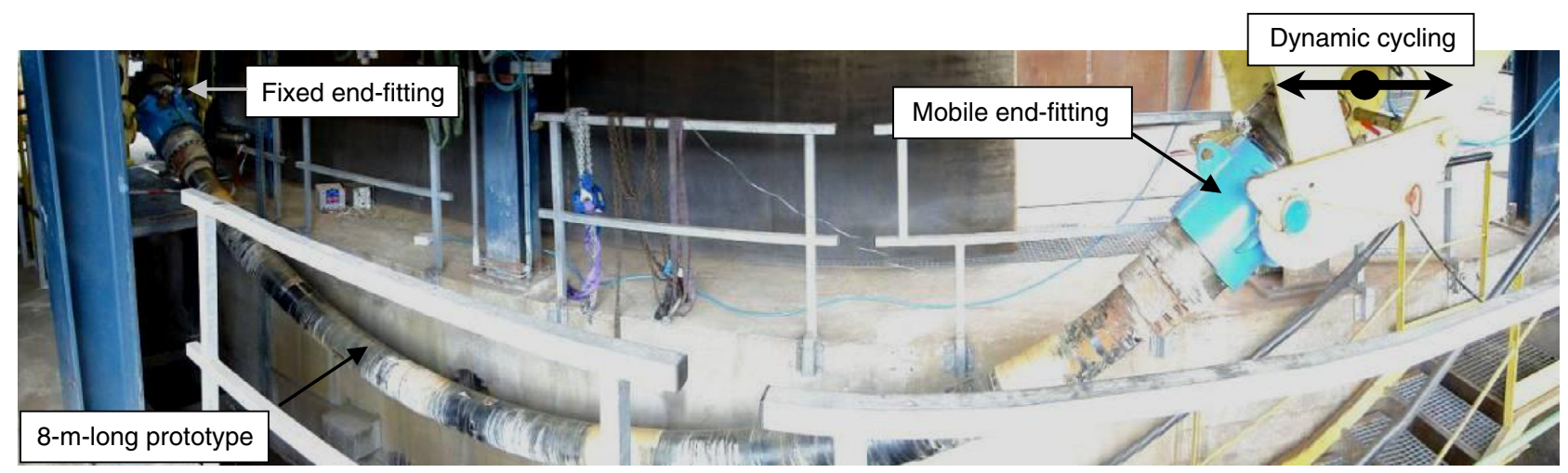

Figure 13

8-meter-long flexible pipe tested in cyclic dynamic bending in a $\mathrm{H}_{2} \mathrm{~S}$-compliant unit (IFPEN, Solaize).

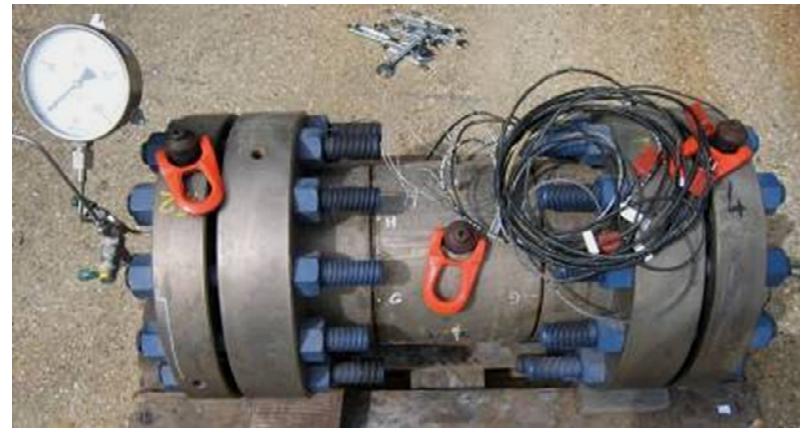

Figure 14

Sample of structure removed every 6 months of effective chemical aging.

- three samples of structure have been taken from the test area in order to be dissected. Two of the three samples have been dissected. The third dissection is ongoing. Observations performed on the anti- $\mathrm{H}_{2} \mathrm{~S}$ layer of the dissected sample confirm the predicted chemical behavior of the material, and consequently the efficiency of the anti- $\mathrm{H}_{2} \mathrm{~S}$ solution;

- no $\mathrm{H}_{2} \mathrm{~S}$ has been detected in the annulus of the samples.

\section{CONCLUSION}

As a result of a collaboration between IFPEN and Technip, a barrier material against $\mathrm{H}_{2} \mathrm{~S}$ has been successfully developed for large-scale and severe industrial applications. From the development of the material (selection of raw materials, compounding, characterization) to its qualification in a representative environment, multiphysics modeling based on the coupling of Fick diffusion in the polymer and gas-solid reactions enables the interpretation of experimental data and the assessment of the results' relevance. The parameter identification was carried out on the results of immersion tests performed on anti- $\mathrm{H}_{2} \mathrm{~S}$ material samples in several conditions. Then, the robustness of the model was confirmed through the results of middle-scale tests performed on twolayer tubes with a thermal gradient in representative conditions (gas mixture with gasoil, for instance).

Full-scale tests with representative 4.8 " flexible pipe structures are ongoing in static and dynamic configurations. To date, the progression of $\mathrm{H}_{2} \mathrm{~S}$ in the anti- $\mathrm{H}_{2} \mathrm{~S}$ layer is consistent with the KilHyS model predictions.

Since the qualification in static conditions is nearly completed, this new anti- $\mathrm{H}_{2} \mathrm{~S}$ layer will soon be available for static flexible flowline application.

\section{ACKNOWLEDGMENTS}

The authors would like to acknowledge Technip's Product Engineering Department in Le Trait and both the Applied Chemistry and Physical Chemistry Division and the Applied Mechanics Division of IFP Energies nouvelles for their contribution to this development.

\section{REFERENCES}

1 Guidelines on materials requirements for carbon and low alloy steels for $\mathrm{H}_{2} \mathrm{~S}$-containing environments in oil \& gas production (1995) London, UK, EFC Pub. 16, The Institute of Materials.

2 Kermani M.B. (1991) Proc. Conf. Corrosion '91, Cincinnati, OH, USA, NACE, Paper 21.

3 Kane R.D., Horvath R.J., Cayard M.S. (1996) Wet $\mathrm{H}_{2} \mathrm{~S}$ cracking of carbon steels and weldments, NACE International, Houston, TX, USA.

4 NACE Technical Report 1F192 (1993 Revision), Use of Corrosion Resistant Alloys in Oilfield Environments, NACE, Houston, TX, USA, 1993. 
5 Kermani M.B. (2000) Material Optimisation for Oil and Gas Sour Production, Corrosion conference, Paper No 156.

6 Craig B.D. (1993) Sour Gas Design Considerations, SPE Monograph No. 15.

7 Crolet J.L., Maisonneuve G. (2000) Construction of a Universal Scale of Severity for Hydrogen Cracking, NACE Annual Conference, Corrosion 2000, 26-31 March, Orlando, Florida, USA, NACE-00127.

8 Sulfide Stress Cracking Resistant Metallic Materials for Oilfield Equipment, NACE MR0175-2002/ISO 15156.

9 Kermani M.B., Martin J.W., Esaklul K.A. (2006) Materials Design Strategy: Effects of $\mathrm{H}_{2} \mathrm{~S} / \mathrm{CO}_{2}$ corrosion on materials selection, NACE International, Corrosion conference, Corrosion 2006, 12-16 March, San Diego, California, USA, NACE-06121.

10 Plennevaux C., Kittel J., Frégonèse M., Normand B., Ropital F., Grosjean F., Cassagne T. (2013) Contribution of $\mathrm{CO}_{2}$ on hydrogen evolution and hydrogen permeation in low alloy steels exposed to $\mathrm{H}_{2} \mathrm{~S}$ environment, Electrochem. Comm. 26, 17-20.

11 Klopffer M.H., Flaconnèche B. (2001) Transport properties of gases in polymers: Bibliographic review, Oil \& Gas Science and Technology 56, 3, 223-244.

12 Flaconnèche B., Martin J., Klopffer M.H. (2001) Transport properties of gases in polymers: Experimental methods, Oil \& Gas Science and Technology 56, 3, 245-259.

13 Aubry J.C., Saas J.N., Taravel-Condat C., Benjelloun-Dabaghi Z., De Hemptinne J.C. (2002) Moldi (Tm): A fluid permeation model to calculate the annulus composition in flexible pipes, Oil \& Gas Science and Technology 57, 2, 177-192.

14 Crank J. (1979) The Mathematics of Diffusion, Oxford University Press.

15 Peng D., Robinson D.B. (1976) New 2-Constant Equation of State, Industrial \& Engineering Chemistry Fundamentals 15, 1, 59-64.

16 Soave G. (1972) Equilibrium constants from a modified Redlich-Kwong equation of state, Chemical Engineering Science 27, 6, 1197-1203.

17 Redlich O., Kwong J.N.S. (1949) On the Thermodynamics of Solutions. V. An Equation of State. Fugacities of Gaseous Solutions, Chemical Reviews 44, 1, 233-244.
18 Nath S.K., de Pablo J.J. (1999) Solubility of small molecules and their mixtures in polyethylene, Journal of Physical Chemistry B 103, 18, 3539-3544.

19 Nath S.K., Banaszak B.J., de Pablo J.J. (2001) Simulation of ternary mixtures of ethylene, 1-hexene, and polyethylene, Macromolecules 34, 22, 7841-7848.

20 Raharjo R.D., Freeman B.D., Paul D.R., Sarti G.C., Sanders E.S. (2007) Pure and mixed gas $\mathrm{CH}_{4}$ and $n-\mathrm{C}_{4} \mathrm{H}_{10}$ permeability and diffusivity in poly (dimethylsiloxane), Journal of Membrane Science 306, 1-2, 75-92.

21 Raharjo R.D., Freeman B.D., Sanders E.S. (2007) Pure and mixed gas $\mathrm{CH}_{4}$ and $n-\mathrm{C}_{4} \mathrm{H}_{10}$ sorption and dilation in poly (dimethylsiloxane), Journal of Membrane Science 292, 1-2, 45-61.

22 Memari P., Lachet V., Klopffer M.H., Flaconneche B., Rousseau B. (2012) Gas mixture solubilities in polyethylene below its melting temperature: Experimental and molecular simulation studies, Journal of Membrane Science 390, 194-200.

23 Marcilly C. (2005) Acido-Basic Catalysis, Editions Technip.

24 Yagi S., Kunii D. (1955) Studies on combustion of carbon particles in flames and fluidized beds, in Proceedings of the 5th Symposium (International) on Combustion, Hottel H.C. (ed), Reinhold, New York, USA, pp. 231-244.

25 Yagi S., Kunii D. (1961) Fluidized-Solids Reactors with Continuous Solids Feed. I: Residence Time of Particles in Fluidized Beds, Chemical Engineering Science 16, 3-4, 364-391.

26 Levenspiel O. (1999) Chemical Reaction Engineering, 3rd edn., John Wiley \& Sons, Inc., New York, USA, pp. 566-588.

27 Houzelot J.-L. (2000) Réacteurs chimiques polyphasés : couplage réaction/diffusion, Techniques de l'Ingénieur, Traité Génie des Procédés, 5J4012, J4012.1-J4013.2.

Manuscript submitted in May 2014 Manuscript accepted in December 2014 Published online in March 2015

Cite this article as: X. Lefebvre, D. Pasquier, S. Gonzalez, T. Epsztein, M. Chirat and F. Demanze (2015). Development of Reactive Barrier Polymers against Corrosion for the Oil and Gas Industry: From Formulation to Qualification through the Development of Predictive Multiphysics Modeling, Oil Gas Sci. Technol 70, 2, 291-303. 